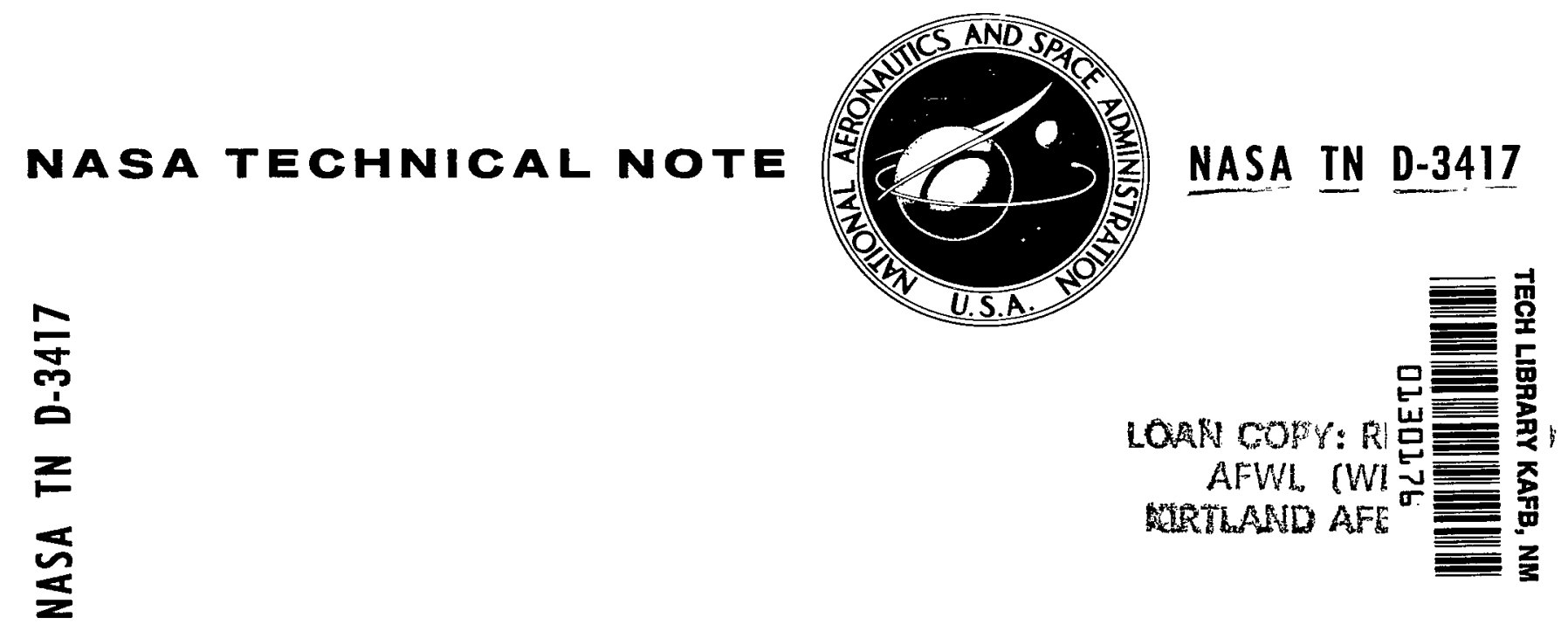

\title{
HIGH PHOTOVOLTAGES IN CADMIUM SULFIDE FILMS
}

by Henry W. Brandhorst, Jr., Ferdinand L. Acampora, and Andrew E. Potter, Jr.

Lewis Research Center

Cleveland, Obio

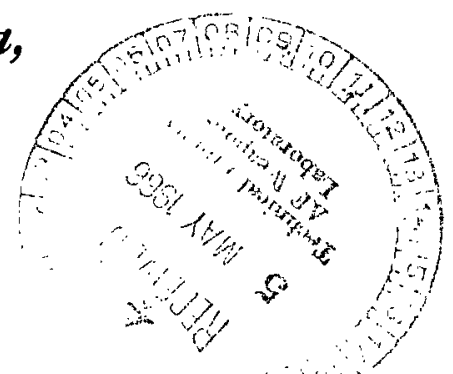

national aeronautics and SPACE administration - Washington, D. C. - APRIL 1966 


\section{HIGH PHOTOVOLTAGES IN CADMIUM SULFIDE FILMS}

By Henry W. Brandhorst, Jr., Ferdinand L. Acampora, and Andrew E. Potter, Jr.

Lewis Research Center

Cleveland, Ohio

\section{NATIONAL AERONAUTICS AND SPACE ADMINISTRATION}

For sale by the Clearinghouse for Federal Scientific and Technical Information Springfield, Virginio 22151 - Price $\$ 1.00$ 


\section{HIGH PHOTOVOLTAGES IN CADMIUM SULFIDE FILMS}

\section{by Henry W. Brandhorst, Jr., Ferdinand L. Acampora, and Andrew E. Potter, Jr. Lewis Research Center}

\section{SUMMARY}

Films of cadmium sulfide (CdS) containing a thickness gradient were prepared which exhibited larger-than-band-gap photovoltages. A necessary condition for the observation of this effect was that the films have high resistances $\left(\sim 10^{11} \mathrm{ohm}\right)$. The decay of the photovoltage after removal of light and the effects of light intensity and temperature on the photovoltage were studied and correlated with a theoretical model. This model is based on the assumption that the voltages are due to a space charge created by a nonuniform distribution of trapped carriers. Trap depths obtained from the decay of the photovoltage showed the presence of traps at $0.08,0.14,0.26$, and 0.41 electron volt. These trap depths were consistent with the depths determined by other investigators using various other methods of measurement. This agreement strongly supports the mechanism proposed for the origin of larger-than-band-gap photovoltages.

\section{INTRODUCTION}

Oblique deposition of thin semiconductor films having high resistances has led to the generation of photovoltages larger than the band gap. These high photovoltages have been observed in films of a large number of semiconductor materials. Initial observation of this effect was made by Starkiewicz, Sosnowski, and Simpson (ref. 1) on lead sulfide films and was consequently confirmed by Berlaga and coworkers (refs. 2 and 3), Schwabe (ref. 4), and Piwkowski (ref. 5). This effect was next observed in cadmium telluride (refs. 6 to 13) and then in zinc sulfide (refs. 14 to 19). Finally, in the last few years, high photovoltages were reported for antimony and bismuth chalcogenides (refs. 10, 20, and 21), germanium (refs. 22 to 25), silicon (refs. 22, 26, and 27), silicon carbide (ref. 26), and gallium arsenide (ref. 28).

Early explanations of this effect were based on the concept of "repetitive stacking faults" or the additive effects of $\mathrm{p}-\mathrm{n}$ junctions. Neither explanation satisfactorily explains the observed behavior of the photovoltage. A more satisfactory explanation has 
been proposed (ref. 26) which ascribes the origin of these photovoltages to a space charge created by a nonuniform distribution of trapped carriers.

In this research, high-resistance films of cadmium sulfide (CdS) showing largerthan-band-gap photovoltages (i. e., $>2.4 \mathrm{eV}$ ) were prepared. The effects of temperature and light intensity on the photovoltage and the decay of the photovoltage after removal of light were studied. In these films the photovoltage appeared to originate from a space charge arising from trapped carriers.

\section{EXPERIMENTAL DETAILS}

The films were prepared by evaporation of CdS in a vacuum of about $10^{-5}$ torr. Quartz plates $1 \frac{1}{2}$ by $1 \frac{1}{2}$ inches were arranged at an angle of about $45^{\circ}$ to the vapor stream at a distance of 17 centimeters from the source. The surface of the substrate was cleaned by a glow discharge before deposition. The crucible temperature was maintained between $900^{\circ}$ and $1000^{\circ} \mathrm{C}$, while substrate temperatures ranged between $280^{\circ}$ and $370^{\circ} \mathrm{C}$. The deposition rate was varied between 5 and $50 \AA$ per minute, and the average film thickness ranged from 100 to $2000 \AA$. This technique yielded films that had a uniform thickness gradient from one side to the other and resistances between $10^{10}$ and $10^{11}$ ohms.

The films consisted of highly oriented hexagonal CdS. Electron diffraction studies showed the presence of large crystallites oriented with the $c$-axis perpendicular to the substrate. X-ray powder patterns yielded no trace of cubic CdS; hence, an upper limit of 1 percent can be set for the cubic phase.

Electrical measurements were made with the apparatus described previously (ref. 26). Briefly, it consisted of a vacuum enclosure with provisions for heating and cooling. Contact to the film was made through spring bronze- or indium-edged clips. The contact material had no appreciable effect on the measurement. Voltages were measured with an electrometer voltmeter which operated a voltage-time recorder. The full intensity, $I_{0}$, of the light reaching the sample was approximately 0.15 watt per square centimeter of light from a $2750^{\circ} \mathrm{K}$ tungsten filament. Wire screens were used to attenuate the light beam for intensity measurements.

\section{RESULTS}

Reproducible fabrication of high-voltage films proved difficult. Only two films having exceptionally high voltages were prepared - one having a voltage of 17 volts, and the other, 12 volts at room temperature. The majority of the films showed voltages less than 1 volt at room temperature. However, at sufficiently low temperatures, most of the 


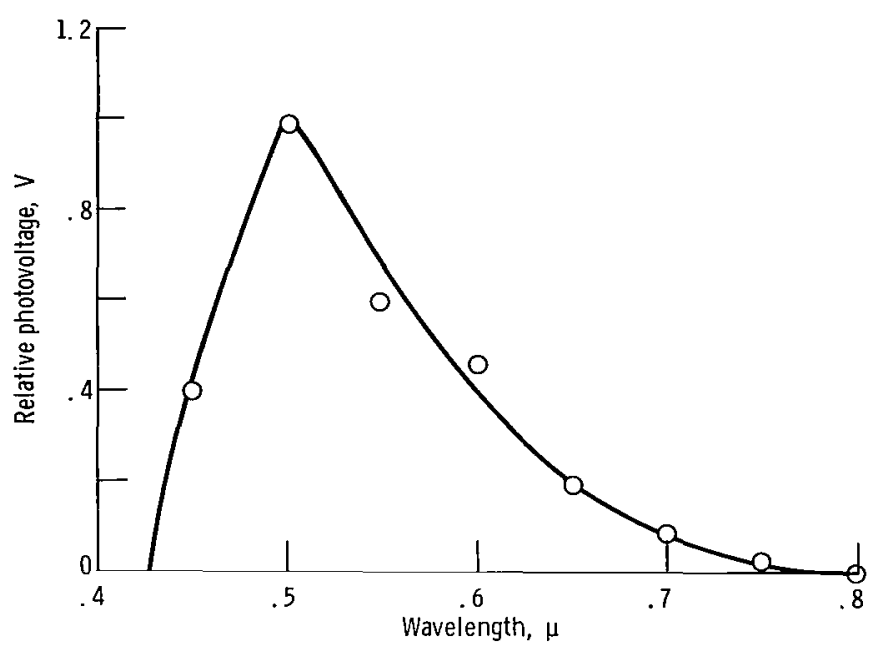

Figure 1. - Spectral response of photovoltage. Film, 1.

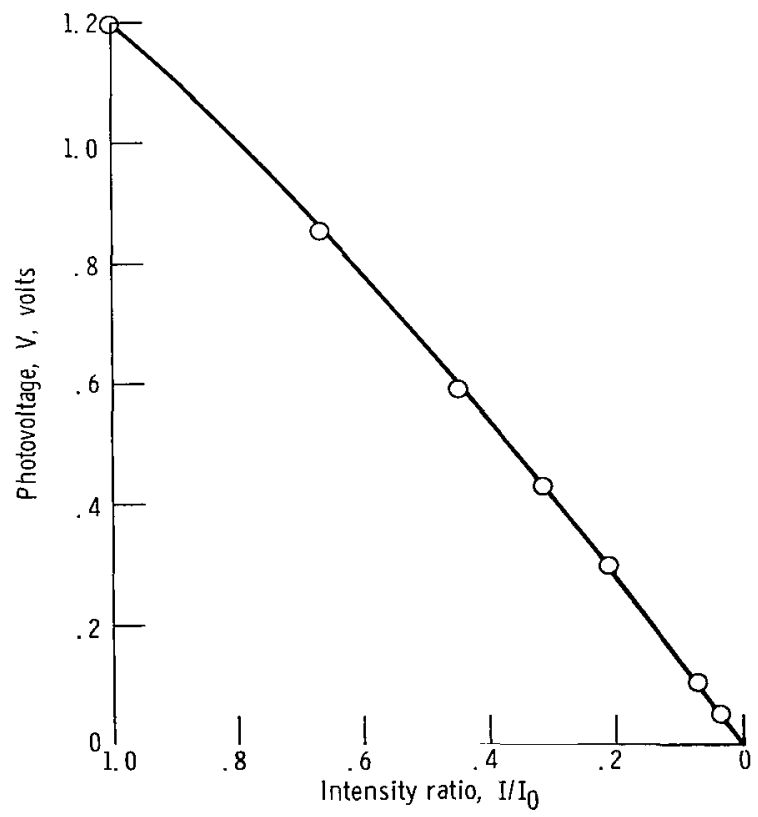

Figure 2. - Variation of photovoltage with light intensity. Film, l; temperature, $27^{\circ} \mathrm{C}$; initial light intensity, 0.15 watt per square centimeter. films exhibited a larger-than-band-gap photovoltage, which indicated a common origin for the voltages in all the films. Since the behavior of all the films was the same with respect to temperature, voltage decay, and other parameters, there appeared to be no reason to distinguish between the expectionally high voltage films and others, insofar as the origin or explanation of the photovoltage is concerned.

\section{Spectral Response of Films}

The spectral response of the photovoltage of one of the CdS films is shown in figure 1. The response peaks at 0.5 micron, which corresponds roughly to the band gap of CdS. However, the response extends out to 0.8 micron, where the energy is much less than the bandgap energy. This must be due to impurity centers which can be ionized by light of an energy less than the band gap.

\section{Effect of Light Intensity on Photovoltage}

Figure 2 shows the effect of light intensity on the photovoltage for a film at room temperature. The variation of photovoltage with intensity was approximately linear at low light intensities. However, above $I / I_{0}=0.3$ (where $I$ is the attenuated intensity) the photovoltage deviated from linearity and became less than expected from a purely linear variation. 


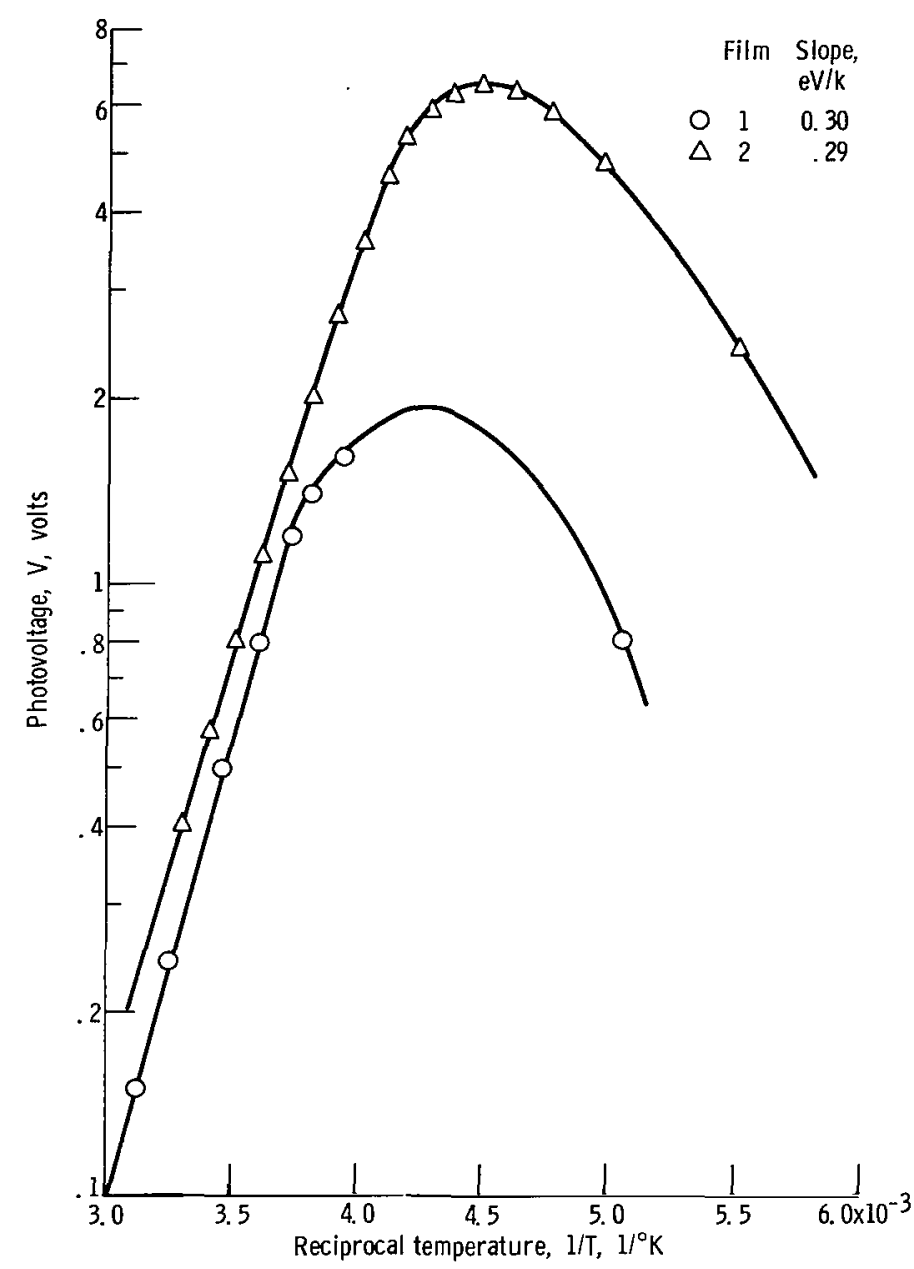

Figure 3. - Temperature dependence of photovoltage.

\section{Effect of Temperature on Photovoltage}

Logarithmic plots of the photovoltage against reciprocal temperature for two CdS films are shown in figure 3. Above room temperature the curve is approximately linear. As the temperature decreases below room temperature, the photovoltage increases to a maximum value at $-40^{\circ}$ to $-50^{\circ} \mathrm{C}$ and then decreases with further temperature decrease. Similar behavior was observed for silicon films (ref. 26).

\section{Kinetics of Photovoltage}

In the case of silicon and silicon carbide films, the photovoltage exhibited a simple exponential decay after the light was removed (ref. 26). Figure 4 shows a typical decay 


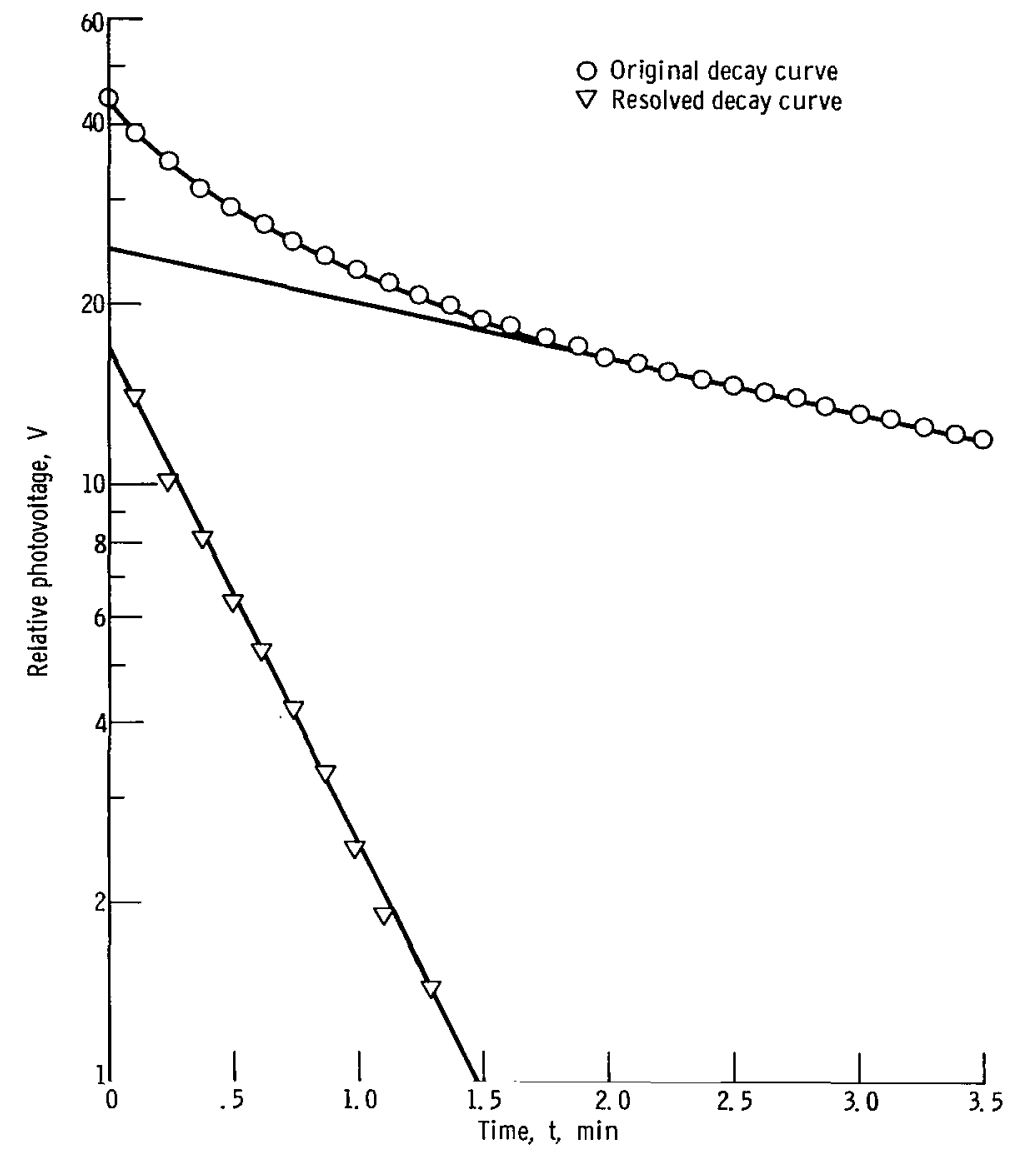

Figure 4. - Decay of photovoltage. Film, 1 ; temperature, $3^{\circ} \mathrm{C}$.

curve for a CdS film. Instead of the linear semilogarithmic dependence of voltage on time expected for simple exponential decay, the plot is curved at short times and becomes linear only at long times. Analysis of the decay curves for CdS films showed that they could be accurately represented as the sum of two or three exponentials. Thus at all temperatures, the decay curve of voltage $V$ as a function of time $t$ could be represented as follows:

$$
\frac{V}{V_{0}}=\sum_{j=1}^{j \geq 2} C_{j} \exp \left(-K_{j} t\right)
$$

where $V_{0}$ is the equilibrium photovoltage, and $C_{j}$ and $\mathbf{K}_{j}$ are constants.

The decay curve shown in figure 4 can be resolved into two components as shown. Decay curves were measured for two films at a number of temperatures, and each curve 
was fitted to equation (1) to obtain the constants $\mathbf{K}_{\mathrm{j}}$.

\section{Effect of Ambient Atmosphere on Photovoltage}

Some degradation of the photovoltage was observed if the films were allowed to stand in air. If a film in this degraded condition was immediately measured in vacuum, the kinetics of the decay were very complicated. After standing for a few hours in vacuum, the photovoltage returned to its original value and the decay kinetics simplified to the form described previously.

\section{THEORETICAL DISCUSSION}

The experimental results obtained with cadmium sulfide films are similar to those previously reported for silicon and silicon carbide films (ref. 26) with the exception of the decay of the photovoltage for which a complex, rather than a simple, exponential decay law was observed. Because no cubic phase was observed in the films, repetitive stacking faults do not contribute significantly to the photovoltage. It is reasonable to attempt explanation of these results in terms of a trap-induced space charge, as was done previously for the silicon and silicon carbide films (ref. 26). In cadmium sulfide the situation is complicated by the presence of many trapping levels (refs. 29 and 30). Consequently, the theory developed previously for a single trap must be extended to the case of multiple traps. Cadmium sulfide is normally n-type, as it was in this research. The large $(2.4 \mathrm{eV})$ band gap allows the observation of deep electron traps (e.g., $0.8 \mathrm{eV}$ ), even in n-type material, since the Fermi level may lie as much as 1.2 electron volts below the conduction band edge. Almost all phenomena reported as arising from traps in cadmium sulfide are attributed to electron rather than hole traps. This is assumed to be the case for the films of this research, and only electron traps in n-type material are considered.

\section{Trap-Induced Photovoltage With Multiple Traps}

From previous work (ref. 26), the voltage produced by a nonuniform distribution of trapped electrons in an $n$-type film is given by

$$
\mathrm{V}=\frac{\mathrm{D}}{\mu \mathrm{n}_{0}}\left[\mathrm{n}_{\mathrm{t}, \ell}\right]_{\mathrm{y}=0}^{\mathrm{y}=\mathrm{y}_{0}}
$$


where $\mathrm{D}$ is the diffusion coefficient, $\mu$ is the mobility of the carriers (assumed equal for holes and electrons for mathematical simplicity), $\mathrm{n}_{0}$ is the equilibrium electron concentration, $n_{t, l}$ is the concentration of trapped $t$ electrons produced by light $\ell$, and $\left[n_{t, \ell}\right]_{y=0}^{y=y_{0}}$ is the difference between the trapped electron concentrations at points $y=y_{0}$ and $y=0$ on the film. Point $y_{0}$ is the position of one electrode on the film surface, and point 0 is the position of the other electrode. Since $\mathrm{D} / \mu=\mathrm{kT} / \mathrm{e}$, where $\mathrm{k}$ is Boltzman's constant and $\mathrm{T}$ is the absolute temperature, equation (2) may be simplified to read

$$
\mathrm{V}=\frac{\mathrm{kT}}{\mathrm{en}}\left[\mathrm{n}_{\mathrm{t}}, \ell\right]_{\mathrm{y}=0}^{\mathrm{y}=\mathrm{y}_{0}}
$$

Adirovich, Rubinov, and Yuabov (ref. 31) have shown that this equation, as originally derived, is limited to voltages less than the band gap. This is a result of the assumption that the distribution of trapped carriers with distance $y$ in the film is given by the quadratic expression $n_{t}=a+b y+c y^{2}$. However, when the distribution of trapped carriers is assumed to be given by the exponential $n_{t}=A \operatorname{exp~By,~the~photovoltage~is~not~limited~}$ to the band gap.

For this distribution, the solution to equation (13) of reference 26 yields for the voltage

$$
\mathrm{V}=\frac{1}{\frac{\mathrm{en} 0}{\mathrm{kT}}-\frac{\epsilon \mathrm{B}^{2}}{4 \mathrm{e}}}\left[\mathrm{n}_{\mathrm{t}, \ell}\right]_{\mathrm{y}=0}^{\mathrm{y}=\mathrm{y}_{0}}
$$

This result is the same as before except for the appearance of an additional constant term $\epsilon \mathrm{B}^{2} / 4 \mathrm{e}$. By variation of $\mathrm{B}$, the photovoltage can be made arbitrarily large and is not limited by the band gap of the material.

For multiple trapping levels, the total concentration of trapped electrons is the sum of the contributions from each of the trap levels. When the expression for the trapped carrier concentration developed in reference 26 is used, the total concentration of trapped electrons $n_{t, \ell}$ is given by 


$$
n_{t, l}=\sum_{i=1}^{i=m} \frac{n_{c, l} N_{t, i} \exp \left(\frac{\Delta E_{i}}{k T}\right)}{N_{c}+n_{c, l} \exp \left(\frac{\Delta E_{i}}{k T}\right)}
$$

where $\mathrm{m}$ is the total number of trapping levels, $\mathrm{n}_{\mathrm{c}, \ell}$ is the density of electrons in the conduction band $c$ caused by illumination, $N_{t, i}$ is the density of the $i^{\text {th }}$ kind of trap, $\Delta E_{i}$ is the energy depth from the conduction band edge of the $i^{\text {th }}$ trap, and $N_{c}$ is the total density of states.

The density of electrons in the conduction band under illumination will be

$$
\mathrm{n}_{\mathrm{c}, l}=\mathrm{n}_{0}+\mathrm{R} \tau
$$

where $\mathrm{R}$ is the rate of photon absorption and $\tau$ is the carrier lifetime. Hence, from equations (4), (5), and (6) the photovoltage is

$$
\mathrm{V}=\frac{\mathrm{n}_{0}+\mathrm{R} \tau}{\frac{\mathrm{en}_{0}}{\mathrm{kT}}-\frac{\epsilon \mathrm{B}^{2}}{4 \mathrm{e}}}\left[\sum_{\mathrm{i}=1}^{\mathrm{i}=\mathrm{m}} \frac{\mathrm{N}_{\mathrm{t}, \mathrm{i}} \exp \left(\frac{\Delta \mathrm{E}_{\mathrm{i}}}{\mathrm{kT}}\right)}{\mathrm{N}_{\mathrm{c}}+\left(\mathrm{n}_{0}+\mathrm{R} \tau\right) \exp \left(\frac{\Delta \mathrm{E}_{\mathrm{i}}}{\mathrm{kT}}\right)}\right]_{\mathrm{y}=0}^{\mathrm{y}=\mathrm{y}_{0}}
$$

At high temperatures and/or low light intensities, equation (7) simplifies to

$$
\mathrm{V}=\frac{\mathrm{n}_{0}+\mathrm{R} T}{\mathrm{~N}_{\mathrm{c}}\left(\frac{\mathrm{e \textrm {n } _ { 0 }}}{\mathrm{kT}}-\frac{\epsilon \mathrm{B}^{2}}{4 \mathrm{e}}\right)}\left[\sum_{\mathrm{i}=1}^{\mathrm{i}=\mathrm{m}} \mathrm{N}_{\mathrm{t}, \mathrm{i}} \exp \left(\frac{\Delta \mathrm{E}_{\mathrm{i}}}{\mathrm{kT}}\right)\right]_{\mathrm{y}=0}^{\mathrm{y}=\mathrm{y}_{0}}
$$

It is interesting to note that as a result of thermal production of electrons, a voltage can exist even in the absence of light, if the trap concentration at $\mathrm{y}=0$ differs from that at $\mathrm{y}=\mathrm{y}_{0}$.

At low temperatures and/or high light intensities, equation (7) simplifies to 


$$
v=\frac{1}{\frac{e n_{0}}{k T}-\frac{\epsilon B^{2}}{4 e}}\left[\sum_{i=1}^{i=m} N_{t, i}\right]_{y=0}^{y=y_{0}}
$$

Observation of the decay of the photovoltage after the light is turned off is a particularly informative experiment. If negligible retrapping occurs and trapped carriers are lost by each trap level according to a simple exponential decay law, the total concentration of trapped electrons $n_{t, l}$ in the film will decay after illumination is stopped according to the equation (ref. 32)

$$
n_{t, \ell}=\sum_{i=1}^{i=m} n_{t, \ell, i}^{0} \exp \left(-P_{i} t\right)
$$

Combining equations (4) and (10) gives for the decay of the photovoltage

$$
v=v_{0}\left[\sum_{i=1}^{i=m} \frac{n_{t, \ell, i}^{0}}{n_{t, l}^{0}} \exp \left(-P_{i} t\right)\right]_{y=0}^{y=y_{0}}
$$

where $v_{0}$ is the equilibrium photovoltage, $n_{t, l}^{0}$ is the total density of trapped carriers under illumination (both obtained from eqs. (4) and (10) at time $t=0$ ), $n_{t, l, i}^{0}$ is the density of carrier in the $i^{\text {th }}$ trap under illumination, and $P_{i}$ is the probability that an electron will escape from the $i^{\text {th }}$ trap.

\section{Comparison of Theory and Experiment}

Effect of light intensity on photovoltage. - Equation (8) indicates that, at low light intensities, the photovoltage should vary linearly with light intensity. Reference to the experimental results in figure 2 (p. 3) shows that this is the case below $I / I_{0}=0.3$. Above $1 / \mathrm{I}_{0}=0.3$, the photovoltage does not increase with light intensity as rapidly as a linear rate. This is probably the beginning of saturation of the traps, since equation (9) shows that the voltage will reach a constant value at sufficiently high light intensities when the traps are all filled.

Effect of temperature on photovoltage. - Equation (8) shows that at high temperatures, the photovoltage should vary with the temperature as the sum of several exponential terms; therefore, a semilogarithmic plot of voltage against reciprocal temperature 
should, in general, be curved. However, it is possible that straight sections will occur in temperature ranges where only one trapping level predominates either because of the depth or the trap concentration or both. The experimental results (fig. 3) show this to occur, with an approximately linear portion between $0^{\circ}$ and $50^{\circ} \mathrm{C}$. Since only one trapping level contributes to the photovoltage in this region, equation (8), for a single trap, shows that the energy depth of the trap can be calculated from the slope. This was done, with the result that the trap depth for film 2 was 0.29 electron volt and that for film 1 was 0.30 electron volt.

At lower temperatures, the photovoltages reach a maximum and then decrease with further temperature decreases. Presumably, this behavior is the result of saturation of the traps; equation (9) shows that the voltage will reach some constant value when all traps are filled. There is no reason to expect this constant value to be larger than the value at room temperature, since it depends on the details of the trap distribution.

Effect of ambient atmosphere on photovoltage. - Degradation of the photovoltage after the film stands in air can be expected from equation (8) because the ambient atmosphere changes the surface recombination velocity and thus alters the carrier lifetime. The complex decay is expected because the various surface states created by this adsorption act as additional trapping centers. It has been shown by Reed and Scott (ref. 33) that oxygen is the active component in air which degrades the photoresponse of CdS crystals by producing two surface states. These surface states increase the surface recombination velocity and thus lower the lifetime.

Kinetics of photovoltage decay. - As discussed previously, the decay of the voltage after the light was removed could be represented by a sum of two or more exponentials. Comparison of the experimental equation (1) with the theoretical equation (11) shows that the experimental decay constants $\mathbf{K}_{\mathbf{j}}$ should equal the escape probability $\mathbf{P}_{\mathbf{i}}$ of an electron from the $i^{\text {th }}$ trap. If this is assumed to be the case, the identity of $K_{j}$ with $P_{i}$ can be used to determine the energy depth $\Delta E_{i}$ of the $i^{\text {th }}$ trap, since (ref. 32)

$$
P_{i}=N_{c} v_{t, i} \exp \left(\frac{-\Delta E_{i}}{k T}\right)
$$

where $v$ is the thermal velocity of electrons and $s_{t, i}$ is the capture cross section of the traps. Thus, semilogarithmic plots of $K_{j}$ against $1 / T$ should be straight lines with slopes of $-\Delta \mathrm{E}_{\mathrm{i}} / \mathrm{k}$.

The decay constants $K_{j}$ were calculated from equation (1) and the experimental decay curves at various temperatures. As predicted, plots of $\ln \mathrm{K}_{\mathrm{j}}$ against $1 / \mathrm{T}$ were straight lines. Experimental data for film 1 are shown in figure 5, Reciprocal decay constants (analogous to lifetimes) were plotted in figure 5 so that positive slopes were obtained. For this film, three different lines were obtained, which suggests the presence 


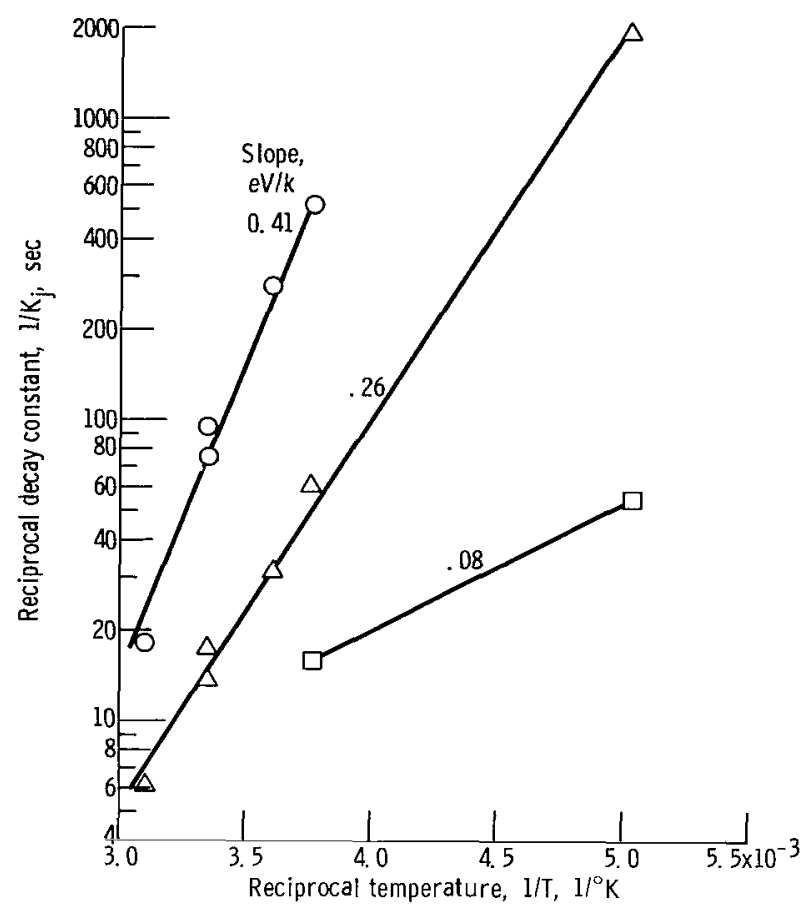

TABLE I. - TRAP DEPTHS IN

CADMTUM SULFIDE FILMS

FROM VOLTAGE DECAY

\begin{tabular}{|c|c|c|}
\hline \multirow[t]{2}{*}{ Film } & $\left\{\begin{array}{c}\text { Temperature } \\
\text { dependence of } \\
\text { photovoltage }\end{array}\right.$ & $\begin{array}{c}\text { Temperature } \\
\text { dependence of } \\
\text { decay constants }\end{array}$ \\
\hline & Trap de & pth, $\Delta \mathrm{E}, \mathrm{eV}$ \\
\hline \multirow[t]{3}{*}{1} & $\ldots$ & 0.08 \\
\hline & 0.30 & .26 \\
\hline & $-\cdots$ & .41 \\
\hline \multirow[t]{4}{*}{2} & ---- & 0.09 \\
\hline & --- & .14 \\
\hline & 0.29 & .27 \\
\hline & $--\ldots$ & .40 \\
\hline
\end{tabular}

Figure 5. - Determination of trap depth from temperature dependence of decay constant. Film, 1.

of at least three distinct and different trapping levels. Trap depths were calculated from the slopes of these curves, and the results for two films are summarized in table I. In general, both films exhibited the same trapping levels.

The 0.08-electron-volt curve was difficult to resolve in the presence of the other curves around room temperature. Only at low temperatures, where the decay time became quite long, could meaningful data be obtained. Therefore, it appears that the 0.08electron-volt traps are present in a low concentration relative to those at 0.26 and 0.41 electron volt or the capture cross sections are quite different. There was also evidence of traps whose depth was greater than 0.41 electron volt, as indicated by a long-lived tail on the decay curve, but the traps could not be accurately resolved. Attempts at resolving this component by going to higher temperatures were not successful because the photovoltage decreased so rapidly in this region that noise obscured the data.

\section{Trap Depths Determined by Other Techniques}

Because the theory upon which equation (11) is based was derived from the assumption that the photovoltage was produced from a space charge created by a nonuniform distribution of trapped carriers, it was of interest to compare the trap depths obtained in this study with depths determined by other techniques. 
Nicholas and Woods (ref. 29), have summarized the trap depths in CdS obtained by several authors. They have established the existence of six discrete sets of traps at depths of $0.05,0.14,0.25,0.41,0.63$, and 0.83 electron volt. Two additional traps at 0.33 and 0.51 electron volt have also been reported (ref. 29) but were not identified in the work of Nicholas and Woods.

In a second paper (ref. 30), Woods and Nicholas attempted to identify the nature of the crystal defects responsible for the trapping centers in CdS. The 0. 05-, 0. 14-, and 0. 25electron-volt traps were observed most frequently in cadmium-rich crystals and have been assigned to various types of sulfur vacancies. The 0.63 -electron-volt center was observed only in sulfur-rich crystals, while the 0.41 - and 0.83 -electron-volt centers usually rccurred together and were found in both sulfur-rich and cadmium-rich crystals. These latter traps were thought to be complexes of associated cadmium and sulfur vacancies in nearest neighbor sites. Trapping centers observed in the present study are consistent with those found previously in

TABLE II. - COMPARISON OF TRAP DEPTHS IN CADMIUM SULFIDE

\begin{tabular}{|c|c|c|}
\hline Present work & Nicholas and Woods ${ }^{a}$ & Büget and Wright ${ }^{b}$ \\
\hline \multicolumn{3}{|c|}{ Trap depth, $\Delta \mathrm{E}, \mathrm{eV}$} \\
\hline 0.08 & 0.05 & --- \\
\hline .14 & .14 & 0.16 \\
\hline .26 & .25 & .24 \\
\hline .41 & .41 & .45 \\
\hline--- & .63 & .63 \\
\hline--- & .83 & .82 \\
\hline
\end{tabular}

${ }^{a}$ Ref. 29.

${ }^{\mathrm{b}}$ Ref. 34 . cadmium-rich material. The center at 0.83 electron volt could not be resolved because of the long decay time involved.

Büget and Wright (ref. 34) have also found traps at similar depths. From the Hall effect, conductivity, and spacecharge-limited current measurements they indicate levels at $0.16,0.24,0.45$, 0.63 , and 0.82 electron volt.

The trap depths obtained by these authors are summarized in table $I I$ and compared to the present work. The good agreement between the trap depths de-

termined independently by a variety of authors and methods and the depths determined from the analysis of the decay of these larger-than-band-gap photovoltages appears to confirm the mechanism proposed for these voltages. It is probable that the larger-thanband-gap photovoltages observed in other materials also originate from trapped carriers.

\section{SUMMARY OF RESULTS}

Films of cadmium sulfide containing a thickness gradient were prepared which exhibited larger-than-band-gap photovoltages. The decay of the photovoltage after removal of light and the effect of light intensity and temperature on the photovoltage were studied. These results were correlated with a model based on the assumption that these voltages 
are due to a space charge created by a nonuniform distribution of electrons trapped at several levels. Analysis of the decay of the photovoltage showed the presence of trapping levels at $0.08,0.14,0.26$, and 0.41 electron volt. These same levels have also been observed in cadmium sulfide by other investigators using various methods of measurement. Agreement of trap depths from the decay of the photovoltage with trap depths determined by other methods strongly supports the mechanism proposed for the origin of this effect.

Lewis Research Center,

National Aeronautics and Space Administration, Cleveland, Ohio, February 18, 1966.

\section{REFERENCES}

1. Starkiewicz, J.; Sosnowski, L.; and Simpson, O.: Photovoltaic Effects Exhibited in High-Resistance Semiconducting Films. Nature, vol. 158, July 6, 1946, p. 28.

2. Berlaga, R. Y.; and Strakhov, L. P.: The EMF Arising From the Illumination of Lead Suphide Photoresistors. Z. Tech. Fiz., vol. 24, no. 5, 1954, p. 943.

3. Berlaga, R. Y.; Rumsh, M. A.; and Strakhov, L. P.: Photoelectromotive Force and Lead Sulfide Photoconductivity. Z. Tech. Fix., vol. 25, 1955, pp. 1878-1882.

4. Schwabe, G.: Directionally Dependent Photoeffect in PbS Layers. Z. Naturforsch. , vol. 10a, no. 1, Jan. 1955 , p. 78.

5. Piwkowski, T.: PbSe and PbTe Infra Red Detectors. Acta Physiol. Polon., vol. 15, no. 4, 1956, pp. 271-274.

6. Pensak, L.: High-Voltage Photovoltaic Effect. Phys. Rev., vol. 109, no. 2, Jan. 15, 1958 , p. 601 .

7. Goldstein, B.: Properties of Photovoltaic Films of CdTe. Phys. Rev., vol. 109, no. 2, Jan. 15, 1958, pp. 601-603.

8. Goldstein, B.; and Pensak, L.: High-Voltage Photovoltaic Effect. J. Appl. Phys., vol. 30 , no. 2, Jan. 1959, pp. 155-161.

9. Pensak, L.: Effect of Gases on the High Voltage Photovolatic Effect. Structure and Properties of Thin Films, C. A. Neugebauer, J. B. Newkirk, and D. A. Vermilyea, eds., John Wiley \& Sons, Inc., 1959, pp. 503-507. 
10. Lyubin, V. M.; and Fedorova, G. A.: High-Voltage Photoelectromotive Forces in Thin Semiconductor Layers. Soviet Phys. -Doklady, vol. 5, no. 6, May-June 1961, pp. $1343-1345$.

11. Kamiyama, Masahide; Haradome, Miyoshi; and Kukimoto, Hiroshi: High-Voltage Photovoltaic Effect in Evaporated CdTe Films. Japan. J. Appl. Phys., vol. 1, no. 4 , Oct. 1962 , pp. 202-209.

12. Semiletov, S. A.: Concerning the High Voltage Photo-EMF in Thin Films of Cadmium Telluride. Soviet Phys. -Solid State, vol. 4, no. 5, Nov. 1962, pp. 909-913.

13. Novik, F. T.: High-Voltage Photo-EMF in "Single-Crystal" Films of Cadmium Telluride. Soviet Phys. -Solid State, vol. 4, no. 11, May 1963, pp. 2440-2441.

14. Ellis, S. G.; Herman, F.; Loebner, E. E. ; Merz, W. J.; Struck, C. W. ; and White, J. G. : Photovoltages Larger Than the Band Gap in Zinc Sulfide Crystals. Phys. Rev., vol. 109, no. 5, Mar. 1, 1958, p. 1860.

15. Cheroff, George; and Keller, Seymour P.: Optical Transmission and Photoconductive and Photovotaic Effects in Activated and Unactivated Single Crystals of ZnS. Phys. Rev., vol. 111, no. 1, July 1, 1958, pp. 98-102.

16. Merz, W. J.: The Photovoltaic Effect in Striated ZnS Single Crystals. Helv. Phys. Acta, vol. 31, no. 6, 1958, pp. 625-635.

17. Lempicki, A.: Anomalous Photovoltaic Effect in ZnS Single Crystals. Phys. Rev., vol. 113, no. 5, Mar. 1, 1959, pp. 1204-1209.

18. Cheroff, G.; Enck, R. C. ; and Keller, S. P.: Effects of Polarized Light on Photocurrents and Photovoltages in ZnS. Phys. Rev., vol. 116, no. 5, Dec. 1, 1959, pp. 1091-1093.

19. Neumark, Gertrude F.: Theory of Anomalous Photovoltaic Effect of ZnS. Phys. Rev., vol. 125, no. 3, Feb. 1, 1963, pp. 838-845.

20. Lyubin, V. M. ; and Fedorova, G. A.: High-Voltage Photo-EMF's in Layers of Antimony Triselenide. Soviet Phys. -Solid State, vol. 4, no. 8, Feb. 1963, pp. 14861489.

21. Karpovich, I. A. ; and Shilova, M. V.: High-Voltage Photo-EMF in $\mathrm{Sb}_{2} \mathrm{~S}_{3}$ Films. Soviet Phys. -Solid State, vol. 5, no. 12, June 1964, pp. 2612-2617.

22. Kallmann, H. ; Kramer, B. ; Haidemenakis, E. ; McAleer, W. J.; Barkemeyer, H. ; and Pollak, P. I. : Photovoltages in Silicon and Germanium Layers. J. Electrochem. Soc., vol. 108, no. 3, Mar. 1961, pp. 247-251.

23. Nakai, J.: Photovoltaic Effect of Germanium Thin Film Obliquely Deposited in Vacuum. Oyo Buturi, vol. 31, 1962, pp. 310-318. 
24. Takahashi, Masaru; and Nakai, Junkichi: Spectral Sensitivity of Photovoltaic Effect of Ge Film Obliquiely Deposited in Vacuum. Japan. J. Appl. Phys., vol. 3, no. 6, June 1964, pp. 364-365.

25. Konorov, P. P.; and Liubits, K. : Photo-EMF in Polycrystalline Layers of Germanium. Soviet Phys. -Solid State, vol. 6, no. 1, July 1964, pp. 55-58.

26. Brandhorst, H. W., Jr.; and Potter, A. E., Jr.: High Photovoltages in Silicon and and Silicon Carbide Films and Their Origins From a Trap-Induced Space Charge.

J. Appl. Phys., vol. 35, no. 7, July 1964, pp. 1997-2003.

27. Adirovich, E. I. ; and Yuabov, Yu. M.: Silicon Films With Anomalously High Photovoltage. Soviet Phys. -Doklady, vol. 9, no. 4, Oct. 1964, pp. 296-298.

28. Martinuzzi, Santo: Propriétés photovoltaiques présentées par des couches minces $d^{\natural}$ arséniure de gallium évaporées obliquement. Comptes Rendus, t. 258, no. 6, Feb. 10, 1964, pp. 1769-1773.

29. Nicholas, K. H.; and Woods, J.: The Evaluation of Electron Trapping Parameters from Conductivity Glow Curves in Cadmium Sulfide. Brit. J. Appl. Phys., vol. 15, July 1964, pp. 783-795.

30. Woods, J. ; and Nicholas, K. H.: Photochemical Effects on Cadmium Sulphide Crystals. Brit. J. Appl. Phys., vol. 15, Nov. 1964, pp. 1361-1367.

31. Adirovich, E. I.; Rubinov, V. M.; and Yuabov, Yu. M.: A Microbattery or a Photocell? Akad. Nauk Doklady, SSSR, vol. 164, no. 3, 1965, pp. 529-532.

32. Bube, R. H.: Photoconductivity of Solids. John Wiley \& Sons, Inc., 1960, pp. 278; 286.

33. Reed, C. E. ; and Scott, C. G.: Surface States on Single Crystals of Cadmium Sulphide. Brit. J. Appl. Phys., vol. 15, Sept. 1964, pp. 1045-1050.

34. Büget, U. ; and Wright, G. T. : Electron Energy Levels in Cadmium Sulphide Single Crystals. Brit. J. Appl. Phys., vol. 16, Oct. 1965, pp. 1457-1460. 
"The aeronautical and space activities of the United States shall be conducted so as to contribute. . . to the expansion of human knowledge of pbenomena in the atmospbere and space. The Administration shall provide for the widest practicable and appropriate dissemination of information concerning its activities and the results thereof."

-National Aeronautics and Space Act of 1958

\section{NASA SCIENTIFIC AND TECHNICAL PUBLICATIONS}

TECHNICAL REPORTS: Scientific and technical information considered important, complete, and a lasting contribution to existing knowledge.

TECHNICAL NOTES: Information less broad in scope but nevertheless of importance as a contribution to existing knowledge.

TECHNICAL MEMORANDUMS: Information receiving limited distribution because of preliminary data, security classification, or other reasons.

CONTRACTOR REPORTS: Technical information generated in connection with a NASA contract or grant and released under NASA auspices.

TECHNICAL TRANSLATIONS: Information published in a foreign language considered to merit NASA distribution in English.

TECHNICAL REPRINTS: Information derived from NASA activities and initially published in the form of journal articles.

SPECIAL PUBLICATIONS: Information derived from or of value to NASA activities but not necessarily reporting the results of individual NASA-programmed scientific efforts. Publications include conference proceedings, monographs, data compilations, handbooks, sourcebooks, and special bibliographies.

Details on the availability of these publications may be obtained from:

SCIENTIFIC AND TECHNICAL INFORMATION DIVISION

NATIONAL AERONAUTICS AND SPACE ADMINISTRATION

Washington, D.C. 20546 